DRAFT/FORTHCOMING

Studia Neoaristotelica 10 (2013)

\title{
How to Save Aristotle from Modal Collapse
}

\author{
DEREK VON BARANDY \\ Loyola Marymount University
}

The false and the impossible have not the same significance.

ARISTOTLE, De caelo 281 $33^{1}$

\section{The Problem: Aristotelian Modal Collapse or InConsistency}

According to Jaakko Hintikka, Aristotle embraced the Principle of Plenitude, which is the thesis that "no unqualified possibility remains unactualized through an infinity of time".2 We shall understand the Principle of Plenitude which Hintikka attributes to Aristotle as the conjunction of the following two principles:

$$
\text { (P) } \mathrm{E} p \leftrightarrow \mathrm{N} p
$$

read: eternally $y^{3} p$ is true 4 if and only if necessarily $p$ is true.

(Q) $\mathrm{E} \sim p \leftrightarrow \sim \mathrm{P} p$

read: eternally not- $p$ is true if and only if it is not possible that $p$ is true.

\footnotetext{
${ }^{1}$ All references to Aristotle are from The Complete Works (Princeton: Princeton University Press, 1983). I use the following abbreviated Latin titles: Categories - Cat. On the Heavens De caelo. On Generation and Corruption - De gen. et corr. De Interpretatione - De int. Metaphysics Met.

${ }^{2}$ Jaakko Hintikka, Time and Necessity: Studies in Aristotle's Theory of Modality (New York: Oxford University Press, 1973), 96.

3 By 'eternal' I mean what Hintikka means by it: omnitemporal - true at all times (as opposed to timelessly true).

${ }^{4}$ Here and after I assume bivalence - viz., that $p$ is equivalent to ' $p$ is true' and that, in what follows, $\sim p$ is equivalent to ' $\sim p$ is true'. I realize that many interpret Aristotle in De int. 9 to be rejecting bivalence for all future contingent statements. They may be right, but in this essay I assume that Hintikka is right and they are wrong.
} 
According to W.V.O. Quine, in order for a declarative sentence to count as a statement that is true or false, it must be purified of both ambiguous indexical usage and tense. ${ }^{5}$ Hence, before the declarative sentence "I ate a banana yesterday" can even be false it must be converted to "Derek eats a banana on February 29th 2013." Thus purified of both ambiguous indexical usage and tense, not only is this statement false, its being false guarantees that it is eternally so. ${ }^{6}$ Thus Quine apparently holds the following principle:

$$
\text { (R) } p \leftrightarrow \mathrm{E} p
$$

read: $p$ is true if and only if eternally $p$ is true.

\section{Now consider}

(1) Aristotle's cloak wears out on September 1st, 350 BC, and suppose that (1) is true. On $\mathrm{R},(1)$ is eternally true. On the conjunction of both R and P, (1) is necessarily true. So if Hintikka is right about Aristotle, Aristotle seems to be committed to the view that Aristotle's cloak could not

5 W.V.O. Quine, Elementary Logic (Cambridge: Harvard University Press, 1983), 5-6. Quine's reasons: if we don't purify declarative sentences of ambiguous indexical usage, one and the same declarative sentence, for example, "He kissed me" could be both true and false at the same time. But "Richard kissed Carol" cannot. Regarding tense, if we don't get rid of it, then one and the same declarative sentence "Germany invaded Poland" will be false in 1938 and true in 1940. But the declarative sentence "Germany invades Poland on September 1st, 1939" will always be true if true. Regarding the latter point, I am well aware that in Cat. 5, 4a23-8 Aristotle explicitly says that statements can and do change their truth-values over time. But I see no reason to think that Aristotle would disagree with Quine that the statement "It is raining on August 10th, 350 BC" does not change its truth-value. He will say that "It is raining" can change its truth-value, but this, like Aristotle's other examples, is temporally indefinite. Thus there seems to be no incompatibility between what Aristotle says in Cat. 5, 4a23-8 and R. Furthermore, if a temporally indefinite statement is true it is true at the time in which it is true, and so every temporally indefinite true statement implies a temporally definite counterpart that says when the former is true. For a reason to think that Aristotle should think statements cannot change their truth-values, see Peter van Inwagen, An Essay on Free Will (New York: Oxford University Press, 1983), 35-36.

${ }_{6}^{6}$ W.V.O. Quine, Philosophy of Logic (Cambridge: Harvard University Press, 1986), 13. As Quine puts it: "The general run of eternal sentences, however, are not as august as their [...] name suggest[s]. Any casual statement of inconsequential fact can be filled out into an eternal sentence by supplying names and dates and canceling the tenses of verbs." 
have been cut up instead. Indeed, if Hintikka is right, every temporally definite statement that is true is necessarily true and the distinction between necessity and possibility thereby collapses. But Aristotle disagrees with Hintikka's Aristotle, for the former insists that "[...] it is possible for this cloak to be cut up, and yet it will not be cut up but wear out first". ${ }^{7}$ In other words, though (1) is true, and under R, eternally so, Aristotle says that (1) is not necessarily true. So Aristotle denies P, and by implication, Q as well. But, in all fairness to Hintikka, in De gen. et corr. II, 11, 338a1-3 Aristotle asserts something like P and in De caelo I, 10-12, Aristotle argues for it at length. In the end, Hintikka is ready to throw up his hands and declare that Aristotle is simply inconsistent. ${ }^{8}$ In the remainder of this essay I show how Aristotle may consistently avoid modal collapse.

Let us look more closely at Aristotle's cloak example. Here it is again: "[...] it is possible for this cloak to be cut up, and yet it will not be cut up but wear out first."' Let us name the cloak that wore out 'Aristotle's cloak' and let us assume that this happened on September 1st, 350 BG. So Aristotle has us suppose that

(1) Aristotle's cloak wears out on September 1st, 350 BC,

is true. Suppose that Aristotle would agree with Quine and grant that (1) is eternally true. Nonetheless, Aristotle asserts that (1)'s being eternally true does not make (1) necessarily true. On the contrary, Aristotle says that it is possible for the cloak to be cut up instead. Since being cut up entails not wearing out, to say that the cloak could have been cut up instead is to say that it is possible that the cloak did not wear out. Though (1) is true, Aristotle says that

(2) Aristotle's cloak does not wear out on September 1st, 350 BC,

is nonetheless possibly true. Since (2) is equivalent to the negation of (1), Aristotle says that though (1) is true, $\sim(1)$ is possibly true. Here Aristotle seems to endorse the following principle:

$(\mathrm{S})(p \cdot \mathrm{P} \sim p)$

\footnotetext{
7 De int. 9, 19a13-14.

${ }^{8}$ Jaakko Hintikka, "Comments on Zev Bechler", Knowledge and Inquiry: Essays on Faakko Hintikka's Epistemology and Philosophy of Science, ed. Matti Sintonen (Amsterdam: Rodopi B.V., 1997), 312.

${ }^{9}$ De int. 9, 19a13-14.
} 
read: $p$ is true and possibly not- $p$ is true. ${ }^{10}$

Since (1) and possibly $\sim(1)$ are eternally true iff true (i.e. principle $\mathrm{R}$ is a valid form of inference), $\mathrm{S}$ becomes

$\left(\mathrm{S}^{\prime}\right)[\mathrm{E} p \cdot \mathrm{E}(\mathrm{P} \sim p)]$

read: eternally $p$ is true and eternally possibly $\sim p$ is true.

Recall

(P) $\mathrm{E} p \leftrightarrow \mathrm{N} p$

P says that if $p$ is eternally true then $p$ is necessarily true. But S' says that $p$ 's being eternally true is compatible with $\sim p$ 's being possibly eternally true, which is just to say that $p$ 's being eternally true is not necessarily true. So $\mathrm{S}$ ' and $\mathrm{P}$ contradict. How might we get Aristotle out of this quandary? I think that looking at the context in which Aristotle seems to endorse these incompatible principles will show us a way out.

\section{The Solution: Aristotle in Context: No Modal Collapse And NO INCONSISTENCY}

Though Aristotle seems to argue for P in De caelo I, 11-12, the most explicit statement of P appears in De gen. et corr. II, 11, 338a 1-3, where he says that: "[...] a thing is eternal if it is by necessity; and if it is eternal, it is by necessity." What does Aristotle have in mind by a "thing" when he says "a thing is eternal if it is by necessity"? It is clear from the context that he is talking about heavenly bodies (e.g., the Sun and the moon), and as a gloss of both De caelo I, 11-12, and De gen. et corr. II, 10-11 would show, Aristotle thinks that heavenly bodies by nature are unmoved, ungenerated, incapable of alteration, indestructible, eternal, and necessary. All that this shows is that Aristotle thinks that concrete things that are eternal are also necessary, and vice versa, or

(T) $(x)(\mathrm{E} x \leftrightarrow \mathrm{N} x)$

read: for any [concrete] $x, x$ is eternal if and only if $x$ is necessary.

10 Note that $\mathrm{S}$ bears a strong resemblance to the synchronic notion of possibility championed by Peter John Olivi and further developed by John Duns Scotus. 
But the inference from $(\mathrm{T})$ to

(P) $\mathrm{E} p \leftrightarrow \mathrm{N} p$

is invalid, for statements (pace Quine) are not concrete objects. Perhaps if $\mathrm{P}$ were qualified in such a way as to refer to all and only those statements which have eternal things as their subjects, Aristotle might provisionally accept $\mathrm{P}$ as a legitimate form of inference in that domain of discourse, but this would do nothing to establish P itself as axiomatic in Aristotle's modal thought. ${ }^{11}$

And a similar point could be made about

${ }^{11}$ It might be argued that even if Aristotle only accepts (T), he thereby also accepts

$$
\left(\mathrm{T}^{\prime}\right)(x)(\sim \mathrm{E} x \leftrightarrow \sim \mathrm{N} x)
$$

read: for any $x, x$ is not eternal if and only if $x$ is not necessary. (see Met. 990b29-991a7)

and that if T' is true then no non-necessary thing (e.g. Aristotle's cloak) could exist forever (i.e. eternally). But, if no non-necessary thing can exist forever, it follows that every nonnecessary thing must (of necessity) fail to exist. Formally:

$$
\left(\mathrm{T}^{\prime \prime}\right)(x)[\sim \mathrm{N} x \leftrightarrow \mathrm{N}(\mathrm{C} x)]
$$

read: for any $x, x$ is not necessary if and only if $x$ necessarily fails to exist.

Furthermore, consider

(1) Aristotle's cloak wears out on September 1st, 350 BC,

and assume that (1) is true. (1) entails

(1') Aristotle's cloak fails to exist on September 1st, 350 BC.

By T" and (1), so the claim goes, $\left(1^{\prime}\right)$ is necessarily true. But, if $\left(1^{\prime}\right)$ is necessarily true, then so is (1), and so Aristotle's cloak could not have not worn out. Therefore, Hintikka is right and Aristotle is inconsistent. My response: T does indeed entail T', and T' entails T'. I'll also grant that (1) entails (1'). But this argument makes two invalid moves. First, just because T" and (1) are true, it doesn't follow that (1) is necessarily true, for T" does not specify the time in which $x$ (Aristotle's cloak) fails to exist, nor does it specify the way (e.g. being cut up or wearing out) in which it fails to exist. Second, though (1) entails (1'), for the reason just mentioned, ( $\left.1^{\prime}\right)$ does not entail (1). However logically inept this objection is, it does bring something interesting to the fore. If Aristotle endorses (T) and (U) (see below), then Aristotle thinks that non-eternal things necessarily fail to exist, but he also thinks that both the time and the way in which they fail to exist is not necessary. One might dub this consequence of the conjunction of both $(\mathrm{T})$ and $(\mathrm{U})$ Aristotelian Disjunctivism - that noneternal things necessarily fail to exist at some time or another and in some way or another. 


\section{$\left(\mathrm{S}^{\prime}\right)[\mathrm{E} p \cdot \mathrm{E}(\mathrm{P} \sim p)]$}

Let us look at the context in which Aristotle seems to endorse it. Like the cloak that is worn out but could have been cut up, Aristotle says that a similar point should be made about all things that are subject to generation and corruption:

[...] in general, in things that are not always actual there is the possibility of being and of not being; here both possibilities are open, both being and not being, and consequently, both coming to be and not coming to be. ${ }^{12}$

Here Aristotle is talking about certain things - things that are by nature not eternal - and these things are capable of both being and not being in the sense that they need not have whatever accidents they might in fact have. Formally,

$$
(\mathrm{U})(x)(\sim \mathrm{E} x \longrightarrow\{[\mathrm{A}(\mathrm{F} x) \rightarrow \mathrm{P}(\sim \mathrm{F} x)] \cdot[\mathrm{A}(\sim \mathrm{F} x) \rightarrow \mathrm{P}(\mathrm{F} x)]\})
$$

read: for any [concrete] $x$, if $x$ is not eternal then if $x$ is accidentally $\mathrm{F}$ then $x$ is possibly not $\mathrm{F}$ and if $x$ is accidentally not $\mathrm{F}$ then $x$ is possibly $\mathrm{F}$.

As before, note that

$$
\left(\mathrm{S}^{\prime}\right)[\mathrm{E} p \cdot \mathrm{E}(\mathrm{P} \sim p)]
$$

does not follow from $\mathrm{U}$, for $\mathrm{U}$ refers to concrete objects whereas S' refers to statements. And as before, perhaps if $\mathrm{S}$ ' were qualified in such a way as to refer to all and only those statements whose subjects are not eternal and whose subjects have a certain predicate accidentally, Aristotle might provisionally accept it as a legitimate form of inference in that domain of discourse, but this does little to suggest that $s^{\prime}$ itself is axiomatic in Aristotle's modal thought.

Aristotle seems to accept both $\mathrm{U}$ and $\mathrm{T}$. But $\mathrm{U}$ and $\mathrm{T}$ are consistent, and so Aristotle's modal thought is consistent. Furthermore, U allows for genuine contingency in the world, and so Aristotle should be thought of as friend of unactualized possibilities and a denier of the Principle of Plenitude.

${ }^{12}$ De int. 9, 19a9-12. 


\section{ApPLiGation to ARistotle's Rejection of Fatalism}

The cloak passage appears in De int. 9, where Aristotle rejects fatalism. The fatalistic argument Aristotle addresses goes something like the following. Suppose that tomorrow there will be a sea battle, or that

(3) A sea battle occurs on March $5^{\text {th }}, 2013$,

is true. But (because of R or bivalence?) if (3) is true, then it is true on March 4th 2013 too, and if (3) is true now then tomorrow's sea battle is necessary. Aristotle wants to avoid this conclusion. Aristotle thinks that events like sea battles are composed of things that are by nature subject to generation and corruption, and so what happens with these things is neither inevitable nor necessary. ${ }^{13}$ What follows is that the way statements are true must reflect the way things are: "[...] statements [e.g. (3)] are true according to how the actual things are[...]"14 Since the event picked out by (3) is not necessary, (3), though true, is not necessarily true. Though (3) is true, its being true is consistent with $\sim(3)$ being possibly true as well. And vice versa: had $\sim(3)$ been true instead then (3) would still be possibly true. Aristotle seems to think that all statements have their truth-values eternally, but all statements divide into two proper subclasses: the necessarily true and the contingently true. Formally, we might put it as follows:

$$
\text { (v) } \mathrm{N} p \vee \sim \mathrm{N} p
$$

read: necessarily $p$ is true or not-necessarily $p$ is true.

$$
(\mathrm{W}) \sim \mathrm{N} p \leftrightarrow[\mathrm{E}(\mathrm{P} p) \cdot \mathrm{E}(\mathrm{P} \sim p)]
$$

read: not-necessarily $p$ is true if and only if both eternally possibly $p$ is true and eternally possibly not- $p$ is true.

As formulated, $\mathrm{V}$ and $\mathrm{W}$ range over statements and not concrete objects, and so they are consistent with both

$$
\text { (T) }(x)(\mathrm{E} x \leftrightarrow \mathrm{N} x)
$$

and

13 Important caveat: if Aristotle accepts $\mathrm{T}$ above, he must think that things subject to generation and corruption must undergo corruption. This doesn't conflict with U though - see no. 11 above.

${ }^{14}$ De int. 9, 19 a33. 


$$
(\mathrm{U})(x)(\sim \mathrm{E} x \rightarrow\{[\mathrm{A}(\mathrm{F} x) \rightarrow \mathrm{P}(\sim \mathrm{F} x)] \cdot[\mathrm{A}(\sim \mathrm{F} x) \rightarrow \mathrm{P}(\mathrm{F} x)]\})
$$

where $x$ is a concrete object. ${ }^{15}$

Let us summarize our findings. Aristotle holds that two classes of things (broadly construed) are eternal: at least heavenly bodies as well as statements (supposing that Aristotle would agree with Quine). Aristotle thinks that the former are necessary, and perhaps he could think that the latter are necessary too, but even if he thinks statements themselves are necessary, their mode of truth is necessary only if what they represent is itself necessary. On the other hand, though the statements which represent things that are not by nature eternal may themselves be necessary, their mode of truth is contingent if and only if what they represent is contingent. ${ }^{16}$

15 One might object here (as an anonymous referee does) that my solution implies the reification of abstracta (in this case, propositions) and that Aristotle is no friend of abstracta. This is indeed a problem with my reconciliation attempt, but to my mind, not an insuperable one. One could either adopt a paraphrase of such language that wouldn't commit it to abstracta, or one could develop an Aristotelian theory of abstract objects. For a fascinating attempt at the latter, see Michael Loux, "Toward an Aristotelian Theory of Abstract Objects", Midwest Studies in Philosophy 11 (1986): 495-512.

16 One might wonder here (as another anonymous referee does) how this squares with Aristotle's claim at De int. 9, 19a23-26 that "[w] hat is necessarily is, when it is [...]" Understood exactly as it sounds, Aristotle seems to be saying that all true statements are necessarily such. In my view, Aristotle goes on to make a distinction between what we now call necessitas consequentiae and necessitas consequentis (i.e. the necessity of the consequence and the necessity of the consequent). In terms of the former (the necessity of the consequence), an obtaining of a state of affairs (like a sea battle) necessarily entails the truth of the statement "there is a sea battle at a certain time." The necessity here is merely the relation of logical entailment between the obtaining state of affairs and the statement it makes true (see Cat. 5, 4b9-19 for Aristotle's own similar articulation of the relationship between states of affairs and the truth of statements). But just because what $p$ represents obtaining necessitates the truth of $p$, it does not follow that $p$ itself is necessarily true - that sort of necessity is the necessity of the consequent enjoyed only by statements which represent whatever is necessary per se. Applied to my reconciliation, this would mean that all contingent truths are necessitated by their obtaining state of affairs, but this sort of necessity is not the necessity enjoyed by their necessarily true counterparts. For an indepth development and defense of this interpretation, see Gail Fine, "Truth and Necessity in De Interpretatione 9", History of Philosophy Quarterly 1 (1984): 23-47. 
In sum, Aristotle consistently holds that the merely false and the impossible have not the same significance. ${ }^{17}$

\section{BIBLIOGRAPHY}

ARISTOTLE. The Complete Works. Edited by Jonathan Barnes, Princeton: Princeton University Press, 1983.

FINE, Gail. "Truth and Necessity in De Interpretatione 9". History of Philosophy Quarterly 1 (1984): 23-47.

HintikKA, Jaakko. Time and Necessity: Studies in Aristotle's Theory of Modality. New York: Oxford University Press, 1973.

. "Comments on Zev Bechler". In Knoweledge and Inquiry: Essays on Jaakko Hintikka's Epistemology and Philosophy of Science. Edited by Matti Sintonen, 311-312. Amsterdam: Rodopi B.V., 1997.

LOUX, Michael. "Toward an Aristotelian Theory of Abstract Objects". Midwest Studies in Philosophy 11 (1986): 495-512.

Quine, W.V.O. Elementary Logic. Cambridge: Harvard University Press, 1983.

Philosophy of Logic. Cambridge: Harvard University Press, 1986.

van Inwagen, Peter. An Essay on Free Will. New York: Oxford University Press, 1983.

\footnotetext{
${ }^{17}$ I read an early version of this paper at the 2010 Metaphysics: Aristotelian, Scholastic, Analytic conference at the Strahov Monastery in Prague. I would like to thank the audience and David Oderberg, my session's moderator, for helpful comments on my paper. I have also benefited from discussion with Joshua Blander and Martin Nemoianu, as well as from the comments by two anonymous referees.
} 